\title{
¿PIRATEAR es robar?
}

\author{
Por Axel Gosseries \\ Traducción de Pablo da Silveira \\ Foto de Pablo Porciúncula
}

\begin{abstract}
En este artículo de opinión, el filósofo belga agrega una perspectiva polémica para pensar la propiedad intelectual hoy. Palabras clave: piratería en Internet, propiedad intelectual, consumidores, productores.
\end{abstract}

In this opinion article, the Belgian philosopher adds a polemical perspective to think of the intelectual property today. Key words: Internet piracy, intellectual property, consumers, producers.

Muchos internautas comparten el sentimiento de que hay una diferencia entre robar algo del exhibidor de un comercio y descargar ilegalmente una pieza musical. El asunto podría discutirse desde el punto de vista jurídico, pero lo que aquí me interesa es considerarlo en el plano más general de los principios. Voy a partir de la noción prejurídica de robo, entendido como un acto mediante el cual una persona priva a otra de algo. Desde esta base, voy a intentar contestar en tres etapas a la pregunta ¿piratear es lo mismo que robar?

La pregunta podría responderse por la negativa, argumentando que los bienes en cuestión son no rivales. ¿Qué quiere decir esto? Si usted roba un pan de un comercio y luego lo consume, estará impidiendo que otra persona lo compre y lo consuma. En cambio, el hecho de bajar un archivo de Internet no impide que otros hagan lo mismo. El consumo de un bien no rival no impide que otros también lo consuman. Probablemente este sea uno de los factores que expliquen por qué el pirateo de archivos es visto como algo diferente al robo en un supermercado. Si nos detuviéramos aquí, podríamos concluir entonces que el pirata melómano no es un ladrón.

El carácter no rival de los bienes intelectuales es un rasgo indiscutible, pero sería un error detenerse aquí. ¿Por qué? Porque esta respuesta ignora la dimensión del productor y, en consecuencia, también la del vendedor. En efecto, en una economía donde la mayor parte de la producción de cada uno está destinada a ser consumida por otros, lo que interesa ante todo al productor no es el valor de consumo de los bienes que produce, sino su valor de cambio. Si el panadero trabaja día y noche, no es solamente para comer pan. También lo hace para comprar legumbres, medicamentos o libros. Del mismo modo, el músico profesional no podría sobrevivir escuchando la música que compone y tomando agua fresca. También él necesita comprar pan. En consecuencia, aun si la piratería en Internet se practica sobre bienes no rivales, esto no quita que el pirata sea un ladrón. Tal como ocurre en el caso de un robo en un supermercado, el pirata priva de un ingreso al productory al vendedor.
* El artículo original, "Le piratage, pas toujours du vol", fue publicado el 5 de febrero de 2011 en el suplemento La Libre Entreprise del diario $L a$ Libre Belgique, p. 9. 


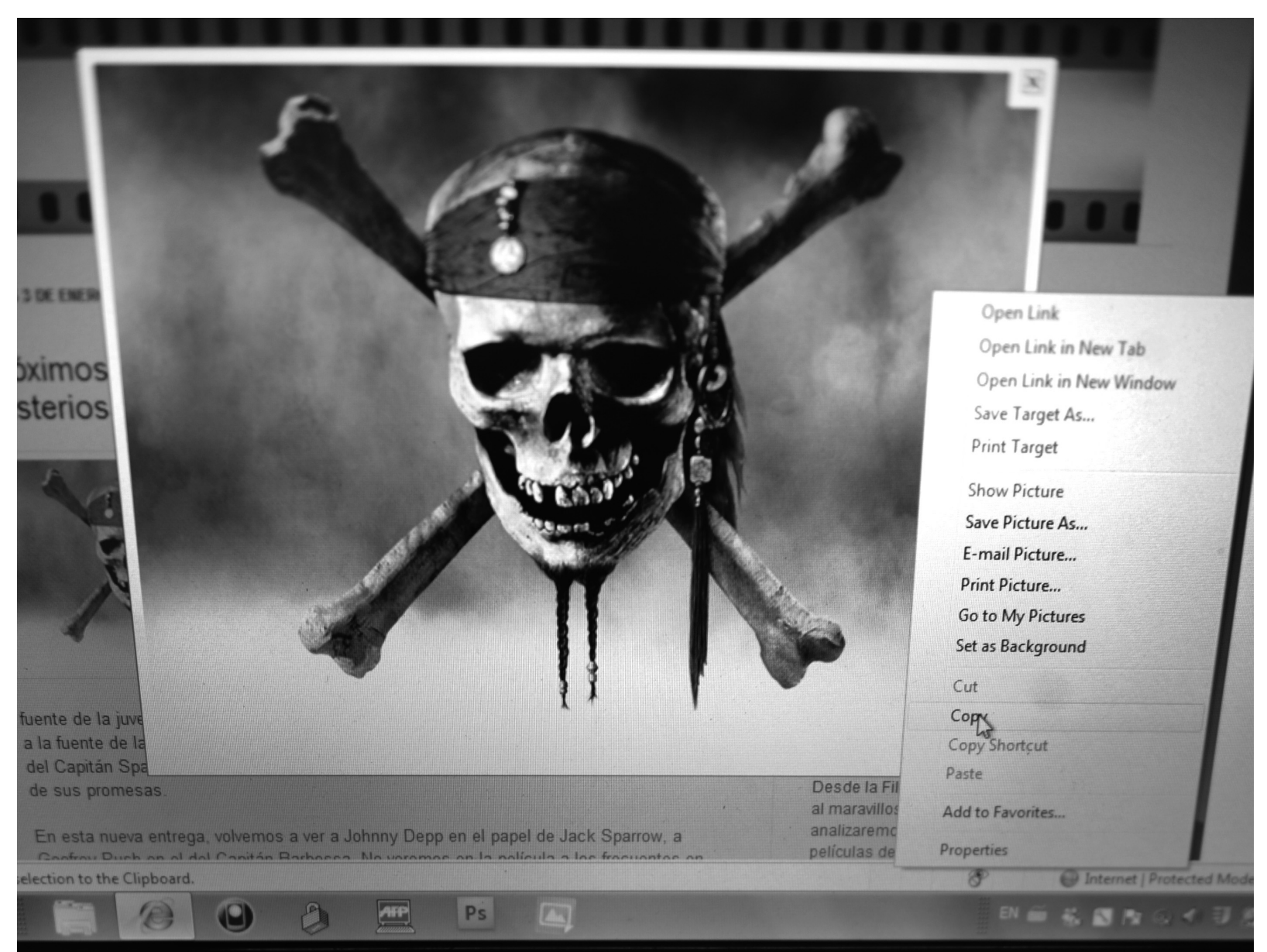

Axel Gosseries:: es filósofo y jurista, profesor en la Cátedra

Hoover de Ética Económica y Social de la Universidad de Lovaina, e investigador del Fondo Nacional de Investigación

Científica de Bélgica.

Entre sus libros se encuentran Intergenerational Justice

(2009), Intellectual Property and Theories of Justice (2008) y Penser la justice entre les générations. De l'affaire Perruche à la réforme des retraites (2004). 
Pero este razonamiento sería incompleto si no se agrega una tercera etapa. ¿Qué ocurre con el consumidor sin poder de compra? ¿Podemos decir que también él, cuando viola la propiedad intelectual, estaría actuando injustamente al privar de su ingreso al productor? La respuesta es negativa, porque el valor de cambio de un bien depende de lo que cada consumidor está dispuesto a ofrecer. Si el consumidor es incapaz de pagar porque apenas tiene lo suficiente para sobrevivir hasta el día siguiente, el valor de cambio de ese producto en relación a ese consumidor será nulo.

Esto no implica solamente que el pirata pobre sería un ladrón con circunstancias atenuantes. En el sentido definido más arriba simplemente no es un ladrón, porque no priva de nada al productor ni menos aún a los demás consumidores. Este razonamiento no tiene nada que ver con la idea de que el fin justifica los medios. No se trata de defender aquí una forma de expropiación en beneficio de los pobres. El argumento se funda simplemente en el hecho de que la función del precio de un bien no rival es diferente de la de un bien rival. Por supuesto, ese precio va a expresar una relación de oferta y demanda entre productor y consumidores. Pero ya no es necesario (tal como ocurre, por ejemplo, en un remate de obras de arte) fijar el precio al nivel de la oferta más alta. Es perfectamente posible ajustar el precio a la capacidad de compra de cada uno sin privar de nada al que ofrece más, porque hay suficiente para todos. En consecuencia, cuando el poder de compra es nulo, el precio puede ser nulo sin riesgo de injusticia hacia los demás consumidores.

¿Cuáles son las consecuencias de este razonamiento? En los países desarrollados, la mayor parte de los piratas disponen de los medios necesarios para pagar lo que descargan ilegalmente. Podemos decir por lo tanto que son ladrones, tanto en el sentido jurídico como en el prejurídico del término, salvo que se considere que los productores no tienen derecho al valor de cambio del cual los priva el pirata.

En cambio, ¿qué podemos decir de una persona que gana menos de dos dólares por día, cuya vida podría ser salvada si consume un medicamento que se vende bajo licencia? Para esa persona, recurrir a medicamentos piratas no sería en absoluto un robo. Y si esa persona, luego de pasar una jornada trabajando para obtener un poco de pan, desea descargar un poco de música sin pagar, tampoco se trataría de un robo.

La cuestión de la propiedad intelectual se plantea entonces de manera muy diferente cuando se trata de los consumidores pobres, tanto los que viven en los países desarrollados como, con mayor claridad, los que viven en otras partes. :- 